\title{
Why is the outcome of transient ischaemic attacks different in different groups of patients?
}

\author{
Graeme J Hankey, Martin S Dennis, James M Slattery, Charles P Warlow
}

The outcomes of each of three large cohorts of patients with transient ischaemic attacks, which were studied in the same country at much the same time with the same methods, were compared and found to be quite different from each other. The differences in outcome were related not only to different strategies of treatment but also to differences in the prevalence and level of important prognostic factors (for example, case mix) and other factors such a the time delay from transient ischaemic attack to entry into the study and the play of chance. The implications for purchasers of health care are that they cannot rely solely on non-randomised comparisons of outcome of patients treated in competing units as a measure of the quality of care (which has only rather modest effects) without accounting for other factors that may influence outcome such as the nature of the illness, the case mix, observer bias, and the play of chance.

Although it is now generally accepted that randomised clinical trials are the best method for evaluating different treatments, some investigators even today have attempted to evaluate treatment by non-randomised comparisons of the outcome of one group of patients treated in one way with the outcome of another group treated in another way. ${ }^{1}$ Purchasers of health care have no choice in the matter because they are not in a position to randomise patients between different units and therefore have to make do with nonrandomised comparisons. Unfortunately, such comparisons of outcome (that is, of prognostic studies or of the results of audit exercises in competing provider units) are prone to several kinds of bias (such as referral bias, migration bias, survival bias, and measurement bias $^{2}$ ). Though it may be argued that adjustment for these biases may be possible by means of complex statistical methods ${ }^{2}$ and these biases are likely to be outweighed by the effect of differences in treatment, this is not necessarily true; the effects of treatment in ischaemic cerebrovascular disease are modest, not large. ${ }^{3-5}$ If the effects were large they would be obvious, and large, randomised trials would be unnecessary.

Our hypothesis is that claims for success or failure of treatment based on different outcomes among different groups of patients with transient ischaemic attack treated in different ways fail to acknowledge just how large the differences in outcome may be, owing to the influence of factors other than the effect of treatment, such as variation in diagnostic and outcome criteria, adequacy of follow up, methods of analysis, and the prevalence or level of important prognostic factors among different cohorts. We examined the outcome of three cohorts of patients presenting with transient ischaemic attacks who were studied in the same country at much the same time (and, in some instances, by the same doctors) with the use of the same diagnostic and outcome criteria (with the exception of trivial strokes) and methods of analysis and who were followed up prospectively and completely, with the aim of identifying important factors influencing outcome.

\section{Patients and methods} PATIENTS

We studied three cohorts of patients with transient ischaemic attacks for whom we had access to the original clinical and survival data: firstly, a series of 469 patients referred to hospital ${ }^{6}$; secondly, a cohort from a randomised trial of treatment comprising 1821 patients who participated in the United Kingdom transient ischaemic attack aspirin trial (courtesy of the trial collaborators) ${ }^{7}$; and, thirdly, an unselected sample of 184 patients in Oxfordshire who were studied as part of the Oxfordshire community stroke project. ${ }^{8}$ To preserve diagnostic and pathogenic uniformity in this study we excluded 601 patients in the aspirin trial who presented with minor stroke and 13 patients who presented with a transient ischaemic attack that was probably not due to atherothromboembolism, lipohyalinosis, or cardiogenic embolism. Although 168 patients in the aspirin trial and 77 patients in the community stroke project were also in the series of 469 patients referred to hospital, we did not exclude these patients because this reflects reality and including them could only minimise rather than exaggerate any differences between the cohorts.

The characteristics of the patients, the methods, definitions, treatments, and the analyses of outcomes of the cohorts have been described previously. ${ }^{6-8}$ Briefly, all patients in each cohort were evaluated and followed prospectively at four to 12 monthly intervals by using standardised criteria for diagnosis and outcome. All patients who had a vascular event of any consequence during the studies were evaluated by their neurologists and all available records, including necropsy reports, were reviewed. In addition, in the aspirin trial the records of each patient were flagged with the Office of Population Censuses and Surveys so that we received a death certificate in the event of their death. Follow up was complete with the exception of one patient in the community stroke project. Follow up of the patients in the aspirin trial continued after the trial was completed (1986) until October 1990, and, although the survival analysis over the longer period has not been published yet, we present here the results for only the subgroup of patients relevant to our study.

\section{STATISTICAL ANALYSIS}

The relative proportions of baseline characteristics, results of investigations, and treatments between cohorts were compared by calculating odds ratios and their $95 \%$ confidence intervals by using standard techniques. ${ }^{9}$ Survival analysis of major outcome events (death; stroke; myocardial infarction; coronary event; stroke, myocardial infarction, or vascular death; stroke, myocardial infarction, or death) was performed

Dr Hankey.

BMF 1993;306:1 107-11 
by means of the actuarial Kaplan-Meier technique. ${ }^{10}$ For the aspirin trial any survival analysis including stroke was confined to major stroke (neurological symptoms lasting longer than one week) because the exact dates of minor strokes (symptoms lasting longer than 24 hours but less than one week) during follow up were not recorded. ${ }^{7}$ In the community stroke project no survival analysis of just major stroke was performed because the definition of a trivial or mild ischaemic stroke (one in which the Rankin score at one month after the stroke was 0 or 1 or had not changed from the score before the stroke) was different from the one for minor stroke in the aspirin trial. ${ }^{11}$ Coronary event and the combined outcome event disabling major stroke or vascular death were not recorded as outcome events in the community stroke project.

The method of calculating the average annual risk $(\mathrm{z} \%)$ over five years of each of the major outcome events has been described. ${ }^{\circ}$ Differences in prognosis between the cohorts were assessed by using the score test procedure provided in the EGRET statistical package within Cox's proportional hazards survival analysis. ${ }^{12-14}$

To determine the degree to which the crude (unadjusted) differences in prognosis among the different cohorts may be accounted for by differences in the prevalence or level of important prognostic factors among the different cohorts we used the results of a previous multiple regression analysis of the clinical and survival data of the series of 469 patients referred to hospital. This analysis provided a prediction equation (mathematical model) of outcome based on the significant independent prognostic factors and a measure of the regression coefficient (hazard ratio) of each prognostic factor. ${ }^{615}$ The prediction equations for stroke, coronary event, and the composite outcome event of stroke, myocardial infarction, or vascular death (derived from the series referred to hospital) were applied to the mean values of the eight important prognostic factors (in the prediction equation) in the aspirin trial and community stroke project. A linear

TABLE I-Actuarial average annual risk of each major outcome event over first five years of follow up from entry into study. Figures are percentages (95\% confidence intervals)

\begin{tabular}{|c|c|c|c|}
\hline Outcome event & $\begin{array}{c}\text { United Kingdom } \\
\text { transient ischaemic attack } \\
\text { aspirin trial } \\
(\mathrm{n}=1821)\end{array}$ & $\begin{array}{l}\text { Hospital } \\
\text { referred } \\
\text { series } \\
(n=469)\end{array}$ & $\begin{array}{l}\text { Oxfordshire } \\
\text { community } \\
\text { stroke project } \\
(\mathrm{n}=184)\end{array}$ \\
\hline $\begin{array}{l}\text { Death } \\
\text { Stroke: }\end{array}$ & $3.6(3.2$ to 4.0$)$ & $4.5(3.4$ to $5 \cdot 6)$ & $7 \cdot 2(5 \cdot 2$ to $9 \cdot 5)$ \\
\hline Minor and major & * & $3.4(2.5$ to 4.6$)$ & $6.7(4.7$ to 8.9$)$ \\
\hline Major & $2 \cdot 5(2 \cdot 2$ to $2 \cdot 8)$ & $2.9(2 \cdot 1$ to 3.8$)$ & \\
\hline Myocardial infarction & $1.4(1.2$ to 1.7$)$ & $2 \cdot 0(1 \cdot 2$ to $2 \cdot 7)$ & $2.5(1.2$ to 4.0$)$ \\
\hline Coronary event & $2.5(2.2$ to 2.9$)$ & $3 \cdot 1(2 \cdot 2$ to $4 \cdot 0)$ & $\dagger$ \\
\hline Disabling major stroke or vascular death & $3.3(2.9$ to 3.7$)$ & $4.0(3.0$ to 5.0$)$ & \\
\hline Stroke, myocardial infarction, or vascular death & $\star$ & $6.5(5 \cdot 3$ to $7 \cdot 8)$ & $8 \cdot 6(6.4$ to 11.0$)$ \\
\hline $\begin{array}{l}\text { Major stroke, myocardial infarction, or vascular } \\
\text { death }\end{array}$ & $5 \cdot 1(4 \cdot 6$ to $5 \cdot 6)$ & $5 \cdot 9(4 \cdot 8$ to $7 \cdot 3)$ & \\
\hline Stroke, myocardial infarction, or death & & $7 \cdot 5(6.2$ to 8.8$)$ & $10 \cdot 3(8 \cdot 0$ to $13 \cdot 1)$ \\
\hline Major stroke, myocardial infarction, or death & $5 \cdot 8(5 \cdot 3$ to $6 \cdot 4)$ & $6 \cdot 8(5 \cdot 6$ to $8 \cdot 3)$ & \\
\hline
\end{tabular}

\#No analysis because minor strokes could not be analysed in survival analysis.

No analysis because coronary events not recorded.

$\ddagger$ No analysis because major stroke not distinguished from minor stroke.

TABLE II-Pairwise comparison of rate of each outcome event between two of three cohorts

\begin{tabular}{|c|c|c|c|}
\hline Outcome event & Score test & Degrees of freedom & $\mathrm{p}$ Value \\
\hline \multicolumn{4}{|c|}{ United Kingdom transient ischaemic attack aspirin trial v hospital referred cohon } \\
\hline $\begin{array}{l}\text { Death } \\
\text { Major stroke } \\
\text { Coronary event } \\
\text { Major stroke, myocardial infarction, or vascular death } \\
\text { Major stroke, myocardial infarction, or death }\end{array}$ & $\begin{array}{l}1 \cdot 4 \\
0 \cdot 4 \\
1 \cdot 8 \\
1 \cdot 3 \\
2 \cdot 1\end{array}$ & $\begin{array}{l}1 \\
1 \\
1 \\
1 \\
1\end{array}$ & $\begin{array}{l}0 \cdot 23 \\
0.52 \\
0 \cdot 18 \\
0 \cdot 25 \\
0 \cdot 15\end{array}$ \\
\hline \multicolumn{4}{|c|}{ Oxfordshire community stroke project v hospital referred cohort } \\
\hline $\begin{array}{l}\text { Death } \\
\text { Stroke } \\
\text { Stroke, myocardial infarction, or vascular death } \\
\text { Stroke, myocardial infarction, or death }\end{array}$ & $\begin{array}{r}7 \cdot 8 \\
12 \cdot 1 \\
4 \cdot 2 \\
6 \cdot 1\end{array}$ & $\begin{array}{l}1 \\
1 \\
1 \\
1\end{array}$ & $\begin{array}{r}0.005 \\
<0.001 \\
0.041 \\
0.013\end{array}$ \\
\hline
\end{tabular}

United Kingdom transient ischaemic attack aspirin trial $v$ Oxfordshire community stroke project

Death

$21 \cdot 9$

$<0.001$ predictor of each outcome event was calculated for each cohort by adding the product of the regression coefficient and mean value of each prognostic variable in the cohort. An "adjusted" estimate of the actuarial average annual risk over five years of an outcome event was then calculated for each cohort and this was compared with the unadjusted estimate. This adjustment is the type of procedure which might be performed by researchers comparing many cohorts from summary information only. It allows for differences in mean values of prognostic variables between cohorts but does not consider what is seldom easily available - that is, differences in the distribution of these variables.

\section{Results}

Table I lists the prognosis of each cohort for the major outcome events. For all outcome events the prognosis of the patients in the aspirin trial was consistently the best; for the patients in the community stroke project it was the worst; and for the patients referred to hospital it was in between. The crude differences between the hospital referred cohort and the patients in the aspirin trial were not significant (table II). There were, however, significant differences between the hospital referred cohort and the patients from the community stroke project (table II) for death; stroke; stroke, myocardial infarction, or vascular death; and for stroke, myocardial infarction, or death. Because stroke was defined slightly differently in the community stroke project and the aspirin trial the only valid comparison was for difference in death rate and this was significant. Of the 10 possible comparisons, five were therefore significant.

Table III shows the proportions of the baseline characteristics and results of investigations and treatments within each cohort. These proportions are compared with each other and illustrated as odds ratios with $95 \%$ confidence intervals in figures 1-3. A potentially important difference between the cohorts that is not illustrated in the figures is the median time from the last transient ischaemic attack to entry into the study; this interval was shortest in the community stroke project (three days) and longest in the aspirin trial cohort (25 days) (see table III).

Previous multiple regression analysis of the clinical and survival data in the hospital referred series of 469 patients showed the significant independent prognostic factors for stroke, myocardial infarction, or vascular death were increasing age (hazard ratio 1.06 for each year), peripheral vascular disease $(2 \cdot 31)$, increasing number of transient ischaemic attacks in three months before presentation $(1.02$ for each attack), male sex (1.98), a combination of carotid and vertebrobasilar attacks at presentation $(2 \cdot 03)$, transient ischaemic attacks of the brain (compared with the eye alone) (1.75), left ventricular hypertrophy (1.72), and the presence of residual neurological signs after the attack (1.93). ${ }^{15}$ Ischaemic heart disease was an additional important prognostic factor for a coronary event. Treatments such as antiplatelet treatment and carotid endarterectomy were also analysed as potential prognostic factors but were not included in the final prediction equation (mathematical model) of outcome because they did not make any significant contribution to the predictive ability of the equation bearing the eight prognostic factors listed above. ${ }^{15}$

By using the regression coefficients of each of the important prognostic factors and the mean value of these prognostic factors in each cohort, we found that the adjusted ratio of the estimate of actuarial average annual risk over five years of each outcome event compared to the hospital referred series moved closer to 1.0 (with the exception of stroke, myocardial 
TABLE $\mathrm{HI}-$ Baseline data and treatments in three cohorts of patients with transient ischaemic attack. Figures are numbers (percentages) unless stated otherwise

\begin{tabular}{|c|c|c|c|}
\hline & $\begin{array}{c}\text { United Kingdom } \\
\text { transient ischaemic attack } \\
\text { aspirin trial }\end{array}$ & $\begin{array}{l}\text { Hospital } \\
\text { referred } \\
\text { (Oxford) }\end{array}$ & $\begin{array}{l}\text { Oxfordshire } \\
\text { community } \\
\text { stroke project }\end{array}$ \\
\hline \multicolumn{3}{|l|}{ Presenting condition: } & 184 \\
\hline Transient cerebral ischaemic attack & $1382(76)$ & $311(66)$ & $152(83)$ \\
\hline Amaurosis fugax & $301(17)$ & $158(34)$ & $32(17)$ \\
\hline Both & 138 & Not available & Not available \\
\hline \multicolumn{4}{|l|}{ Presumed arterial territory: } \\
\hline Carotid & $1361(75)$ & $346(74)$ & $148(80)$ \\
\hline Carotid and veretebrobasilar & $105(6)$ & $36(8)$ & Not available \\
\hline Vertebrobasilar or uncertain & 355 (19) & 87 (19) & $36(20)$ \\
\hline \multicolumn{4}{|l|}{ Median time (interquartile range) from transient } \\
\hline ischaemic attack to entry into study (days) & $25(40)$ & $10(25)$ & $3(6)$ \\
\hline Mean (SD) age (years) & $60.4(9)$ & $62 \cdot 1(12)$ & $69 \cdot 4(12)$ \\
\hline Men & $1303(72)$ & $317(68)$ & $103(56)$ \\
\hline Current smokers & $959(53)$ & $221(47)$ & $50(27)$ \\
\hline Hypertension ${ }^{\star}$ & $552(30)$ & $198(42)$ & $91(49)$ \\
\hline Ischaemic heart disease ${ }^{\star}$ & $385(21)$ & $99(21)$ & $34(18)$ \\
\hline Valvular heart disease $^{\star}$ & $37(2)$ & $71(15)$ & $39(21)$ \\
\hline \multirow{2}{*}{\multicolumn{4}{|c|}{ Evidence of left ventricular strain or left ventricular }} \\
\hline & & & \\
\hline hypertrophy on electrocardiography & $121(7)$ & $46(10)$ & $34(18)$ \\
\hline Cardiomegaly & 165 (9) & $76(16)$ & $56(30)$ \\
\hline Peripheral vascular disease ${ }^{\star}$ & $238(13)$ & 79 (17) & $21(11)$ \\
\hline Carotid bruit & Not available & $141(30)$ & $38(21)$ \\
\hline Residual neurological signs & $109(6)$ & $26(6)$ & $17(9)$ \\
\hline Diabetes ${ }^{\star}$ & $65(4)$ & $25(5)$ & $12(6)$ \\
\hline Mean (SD) blood glucose $(\mathrm{mmol} / \mathrm{l})$ & $5 \cdot 2(2)$ & $5 \cdot 2(1)$ & $5 \cdot 6(2)$ \\
\hline Mean (SD) plasma cholesterol (mmol/l) & $6 \cdot 5(2)$ & $6.7(1.4)$ & $6.9(1.6)$ \\
\hline Hypercholesterolaemia & $592(33)$ & $201(42)$ & $95(52)$ \\
\hline Packed cell volume $>0.50$ & $68(4)$ & $46(10)$ & $29(16)$ \\
\hline Infarction on computed tomography/No of scans done & $122 / 849(14)$ & $52 / 302(17)$ & $35 / 132(27)$ \\
\hline Appropriate/inappropriate to symptoms & Not available & $26 / 26(50)$ & $14 / 18(44)$ \\
\hline Treated with aspirin & $1214(67)$ & $219(47)$ & $105(57)$ \\
\hline Treated with anticoagulants & $109(6)$ & $11(2)$ & $15(8)$ \\
\hline Treated with carotid endarterectomy & $93(5)$ & $55(12)$ & $6(3)$ \\
\hline
\end{tabular}

*Slightly different definitions of disease or risk factor between studies.

infarction, or vascular death in the community stroke project but not to $1 \cdot 0$ (table IV). This suggests that the differences in prognosis among the cohorts cannot be explained solely on the basis of differences in the prevalence and level of these eight prognostic factors, at least within the limitations of the statistical models; other factors such as time from transient ischaemic attack to entry into the study and the play of chance may be important.

\section{Discussion}

There were consistent differences, many of them significant, in the prognosis of patients with transient ischaemic attack among the different cohorts, despite some overlap of patients in two or more cohorts. The usual explanations for differences in prognosis between studies (such as variation in criteria for diagnosis and outcome, pathogenesis, adequacy of follow up, and methods of survival analysis) do not apply here. The differences in prognosis among the three cohorts are therefore probably due to differences in other factors (such as the time delay between the last transient ischaemic attack and entry into the study, treatment strategies and effects, and the prevalence and level of important prognostic factors) and also, at least to some extent, the random play of chance.

TIME DELAY BETWEEN ONSET OF ATTACK AND ENTRY INTO STUDY

The greater delay from the onset of a transient ischaemic attack to entry into the aspirin trial (median
25 days) and the hospital referred series (median 10 days) than the community stroke project (median three days) may have biased these first two cohorts toward a better prognosis for stroke (but not myocardial infarction) than the stoke project because the risk of stroke is greatest in the first few days or weeks after a transient ischaemic attack. ${ }^{68}$ Even if we exclude from the analysis of stroke in the community stroke project the $4.4 \%$ probability of stroke during the first month after a transient ischaemic attack, ${ }^{8}$ however, the average annual risk of stroke over five years after the attack in the stroke project is still higher $(5.6 \%)$ than that of the hospital referred cohort (a comparison was not made with the risk of stroke in the aspirin trial because of the slightly different definitions of stroke; see above).

\section{Baseline characteristics}

More transient ischaemic attacks of brain than eye

More carotid than vertebrobasilar transient ischaemic attacks Age $>65$ years

More men than women Smoking Hypertension

Ischaemic heart disease Valvar heart disease + Atrial fibrillation

Evidence of left ventricular strain or left ventricular hypertrophy on electrocardiography

Cardiomegaly

Peripheral vascular disease Residual neurological signs Diabetes mellitus Hypercholesterolaemia

Packed cell volume $>0.50$ Any "infarction" on computed
tomography

Aspirin treatment Anticoagulant treatment Carotid endarterectomy

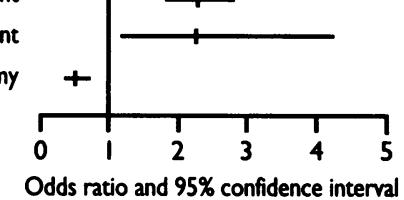

$0-1$ More common in patients $1-5$ More common in patients referred to hospital $(n=469)$ in aspirin trial $(n=1821)$

FIG 1-Relative proportions of baseline characteristics in patients with transient ischaemic attack referred to hospital and those in United Kingdom transient ischaemic attack aspirin trial. Diagram shows odds ratio (small vertical line) and 95\% confidence interval (longer horizontal line) comparing hospital referred patients possessing vascular disease or risk factor with patients in aspirin trial. If odds ratio is 1.0 then prevalence of risk factor is about equal. in two cohorts. If $95 \%$ confidence interval does not overlap with 1.0 then difference in prevalence of risk factor between two groups is significant at $p \leqslant 0.05$

\begin{tabular}{|c|c|c|c|c|c|}
\hline \multirow[b]{2}{*}{ Outcome } & \multirow[b]{2}{*}{ Hospital referred series } & \multicolumn{2}{|c|}{$\begin{array}{l}\text { United Kingdom transient } \\
\text { ischaemic attack aspirin trial }\end{array}$} & \multicolumn{2}{|c|}{ Oxfordshire community stroke project } \\
\hline & & Unadjusted & Adjusted & Unadjusted & Adjusted \\
\hline $\begin{array}{l}\text { Stroke }{ }^{\star} \\
\text { Coronary event† } \\
\text { Stroke, }{ }^{\star} \text { myocardial infarction, or vascular death }\end{array}$ & $\begin{array}{l}1.00 \\
1.00 \\
1.00\end{array}$ & $\begin{array}{l}0.86 \\
0.81 \\
0.86\end{array}$ & $\begin{array}{l}0.96 \\
0.87 \\
0.91\end{array}$ & $\frac{1.97}{1.32}$ & $\begin{array}{l}1.62 \\
1 \cdot 70 \\
1.64\end{array}$ \\
\hline
\end{tabular}

^In hospital referred series $v$ aspirin trial survival analysis of stroke included only major strokes.

†In Oxfordshire community stroke project analysis is for myocardial infarction only and not other coronary events. 


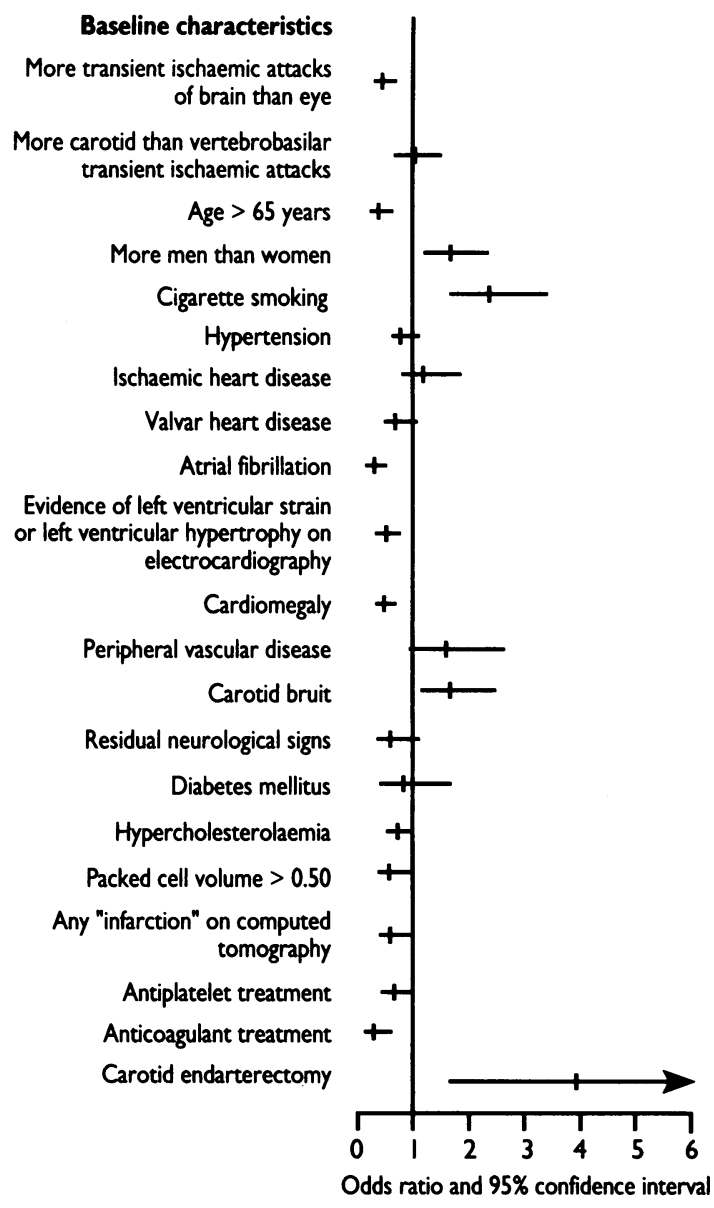

0-1 More common in patients 1-6 More common in patients in community stroke project $(n=184)$ referred to hospital $(n=469)$

FIG 2-Relative proportions of baseline characteristics in patients with transient ischaemic attack in Oxfordshire community stroke project and those referred to hospital. Diagram shows odds ratio (small vertical line) and 95\% confidence interval (longer horizontal line) comparing patients in community stroke project possessing vascular disease or risk factor with patients referred to hospital. If odds ratio is 1.0 then prevalence of risk factor is about equal in two cohorts. If $95 \%$ confidence interval does not overlap with 1.0 then difference in prevalence of risk factor between two groups is significant at $p \leqslant 0.05$

\section{TREATMENT STRATEGIES AND EFFECTS}

The different proportion of patients treated in different ways among the cohorts reflects to some extent the personal preferences of the physicians (for example, the hospital referred series was characterised by a lower rate of use of anticoagulants and higher rate of referral for carotid angiography and endarterectomy); the purpose of the cohort (for example, the greater use of antiplatelet treatment in the aspirin trial because two thirds of patients were randomised to receive aspirin); and other factors such as the age of the patients and their willingness to be investigated and treated.

As the magnitude of the effect of treatments such as antiplatelet treatment ${ }^{3}$ or carotid endarterectomy ${ }^{45}$ is modest rather than large, differences in treatments among the cohorts was probably not the only explanation for differences in prognosis, particularly when the cohorts with the better prognosis did not always have a greater proportion of patients treated with effective treatments (for example, a greater proportion of patients in the community stroke project cohort were treated with aspirin than in the hospital referred series but the prognosis in the stroke project cohort was significantly worse). Also, even if the effect of carotid endarterectomy was large, it is unlikely to have made a measurable impact on the prognosis of the entire cohort as so few patients were treated in this way (see table II).
PREVALENCE AND LEVEL OF IMPORTANT PROGNOSTIC FACTORS

There were consistent differences in the baseline characteristics of the patients referred to hospital and those in the community stroke project (and even between the two hospital referred cohorts), many of which may be traced back to a difference in age among the cohorts. A greater proportion of the younger, hospital referred patients were men and current cigarette smokers whereas a greater proportion of the older patients in the community study were women and patients with hypertension, left ventricular hypertrophy, cardiomegaly, atrial fibrillation, hypercholesterolaemia, raised packed cell volume, and evidence of infarction on cranial computed tomography (see figs 1-3). Many of these observations have been noted by other investigators; the risk of having a transient ischaemic attack or stroke (or coronary event) in middle age is greater in men than in women ${ }^{11} 1617$ and, as people get older, the prevalence of cigarette smoking declines and the prevalence of hypertension, atrial fibrillation, and other vascular risk factors increases. ${ }^{18-22}$ The reason why the patients treated in the community were considerably older is probably that older patients are not referred to hospital and are not entered into randomised trials as often as younger patients.

The higher proportion of patients in the hospital

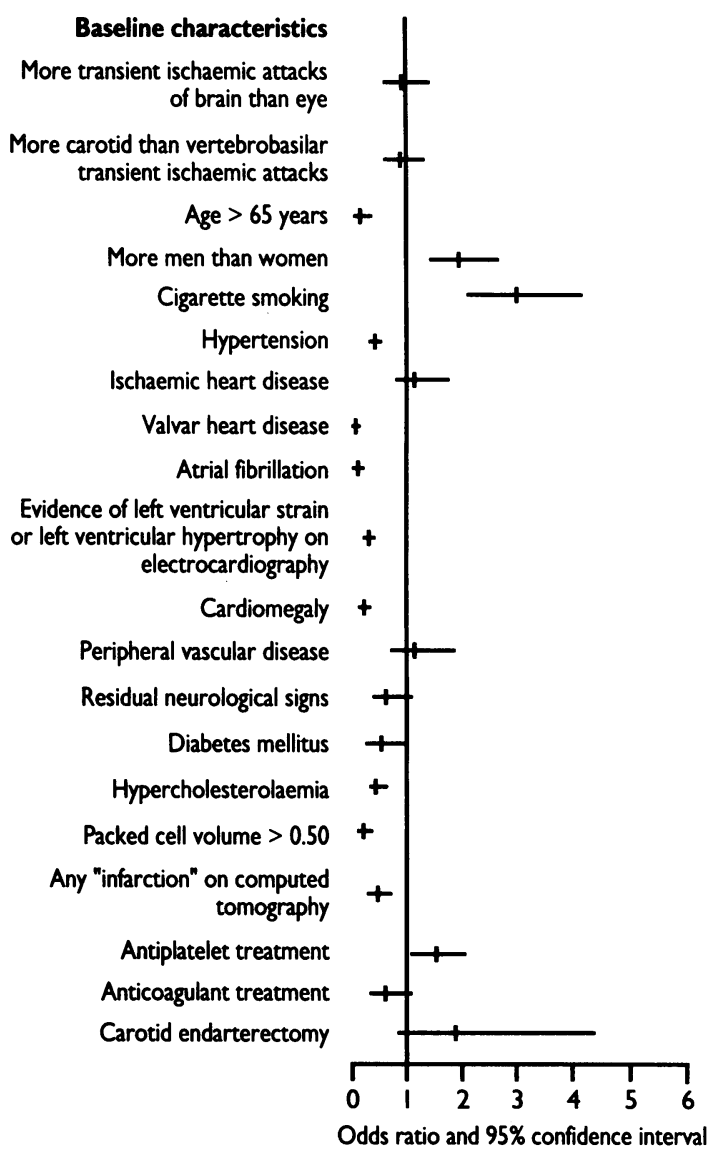

0-1 More common in patients 1-6 More common in patients in community stroke project $(n=184)$ in aspirin trial $(n=1821)$

FIG 3-Relative proportions of baseline characteristics in patients with transient ischaemic attack in Oxfordshire community stroke project and those in United Kingdom transient ischaemic attack aspirin trial. Diagram shows odds ratio (small vertical line) and $95 \%$ confidence interval (longer horizontal line) comparing patients in community stroke project possessing vascular disease or risk factor with patients in aspirin trial. If odds ratio is 1.0 then prevalence of risk factor is about equal in two cohorts. If $95 \%$ confidence interval does not overlap with 1.0 then difference in prevalence of risk factor between two groups is significant at $p \leqslant 0.05$ 
referred series presenting with amaurosis fugax, which is a favourable prognostic factor compared with transient ischaemic attack of the brain, ${ }^{15}$ is because CPW encouraged referral of patients with amaurosis fugax from the Oxford Eye Hospital. The lower proportion of valvular heart disease and atrial fibrillation in the aspirin trial was due to selection bias as patients taking anticoagulants (usually for valvular heart disease or atrial fibrillation) were excluded from the trial (although obviously some patients were prescribed anticoagulants after randomisation and were therefore not excluded).

Adjustment for the differences in the prevalence or level of important prognostic factors among the studies accounts for some but not all of the differences in prognosis; the adjustments are generally in the right direction but do not totally abolish the differences. This illustrates how even sophisticated mathematical equations of prediction are not good enough to adjust completely for differences in prognosis among different populations of patients with transient ischaemic attack. One reason is that they do not take account of the time from the attack to entry into the study, but, moreover, they cannot be expected to work very well in predicting the outcome of cohorts of patients based on the mean values of the prognostic factors in the cohort. They should be used for their prespecified purpose, which is to predict outcome in individual patients (that is, on a patient by patient basis by using the values of the prognostic factors of the individual patient).

\section{ROLE OF CHANCE}

The differences in prognosis of the three cohorts are unlikely to be due entirely to chance because the differences were consistent across outcome events and the $95 \%$ confidence interval of the risk of some of the outcome events in any one cohort, particularly in the community stroke project cohort, did not overlap with the $95 \%$ confidence interval of the estimate of the risk of the respective outcome events in the other cohorts (see table I).

\section{ANALYSIS OF DIFFERENT OUTCOME EVENTS}

Despite the fact that the definitions of outcome events were standardised and consistent for all cohorts (with the exception of trivial strokes), the survival analysis in the aspirin trial was restricted to major stroke because the exact dates of minor strokes were not recorded. As $15 \%$ of the patients who suffered a stroke during follow up actually suffered a minor stroke (which were not included as strokes in the survival analysis) the actuarial average annual rate of stroke may have been underestimated by about $15 \%$. Nevertheless, this is probably not the sole explanation for the lower rate of stroke in the aspirin trial because the actuarial average annual rates of major stroke and disabling major stroke or vascular death (see table I) were lower, although not significantly so, in the aspirin trial cohort than in the hospital referred series. Also, the prognosis for outcome events other than stroke, such as death and myocardial infarction, was better in the aspirin trial.

It is interesting to note that the same clinicians participating in different studies of patients with transient ischaemic attack at the same time used (slightly) different definitions (for example, for trivial strokes, in this case). The difficulties encountered in achieving standardised diagnostic and outcome criteria are evident throughout the published reports on transient ischaemic attacks and emphasise just how cautious one needs to be in comparing outcomes between different studies, even when the outcome events have almost the same names and have even been identified by the same doctors.
CONCLUSION

The differences in prognosis of the three different cohorts of patients with transient ischaemic attack in this study must reflect in part the differences in the prevalence or level of important prognostic factors (such as age) as well as differences in treatment. This re-emphasises what most clinical scientists already know and what purchasers of health care are now discovering: comparing outcomes of non-randomised cohorts or of patients treated in different competing units is most unlikely accurately to detect the usually rather modest effects of different treatments. Very large differences in outcome, however, larger than those detected in this study, might reflect a true difference in the effect of treatment which would bear further investigation.

These findings have widespread implications and may be generalised from transient ischaemic attacks to other disorders; when comparing the outcome of patients treated in different ways it is important not only to consider the nature of the illness which the patients suffer and the quality and effectiveness of the care given but also the type of patient included in the study (that is, the prognostic factors influencing case mix), how soon after the onset of the illness the patients were referred, the way(s) in which outcome was measured, and the play of chance (or luck).

Dr Hankey and Dr Dennis were supported by the Stroke Association and Mr Slattery by the Medical Research Council. The data from the United Kingdom transient ischaemic attack aspirin trial were provided by the trial collaborators and those from the Oxfordshire community stroke project by Drs J M Bamford and P A G Sandercock.

1 Howard G, Brockschmidt JK, Rose LA, Frye-Pierson JL, Crouse JR, Evans $\mathrm{GW}$, et al. Changes in survival after transient ischaemic attacks: observation comparing the 1970s and 1980s. Neurology 1989;39:982-5.

2 Fletcher RH, Fletcher SW, Wagner EH. Clinical epidemiology. The essentials. 2nd ed. Baltimore: Williams and Wilkins, 1988:116-26.

3 Antiplatelet Trialists' Collaboration. Secondary prevention of vascular disease by prolonged antiplatelet treatment. $B M \mathcal{F} 1988 ; 296: 320-31$.

4 European Carotid Surgery Trialists' Collaborative Group. MRC European carotid surgery trial: interim results for symptomatic patients with severe (70-99\%) or with mild (0-29\%) carotid stenosis. Lancet 1991;337:1235-43.

5 North American Symptomatic Carotid Endarterectomy Trial (NASCET) Collaborators. Beneficial effect of carotid endarterectomy in symptomatic patients with high-grade carotid stenosis. N Engl f Med 1991;325:445-53.

6 Hankey GJ, Slattery JM, Warlow CP. The prognosis of hospital-referred transient ischaemic attacks. I Neurol Neurosurg Psychiatry 1991;54:793-802.

7 UK-TIA Study Group. The United Kingdom transient ischaemic attack (UK-TIA) aspirin trial: final results. I Neurol Neurosurg Psychiatry 1991;54 1044-54.

8 Dennis M, Bamford J, Sandercock P, Warlow C. Prognosis of transien ischaemic attacks in the Oxfordshire community stroke project. Stroke 1990;21:848-53.

9 Morris JA, Gardner MJ. Calculating confidence intervals for relative risks, odds ratios, and standardised ratios and rates. In: Gardner MJ, Altman DG, eds. Statistics with confidence. London: $B M$ F, 1989:50-63.

10 Kaplan EL, Meier P. Nonparametric estimations from incomplete observations. American Statistical Association foumal 1958;53:457-81.

11 Dennis MS, Bamford JM, Sandercock PAG, Warlow CP. A comparison of risk factors and prognosis for transient ischaemic attacks and minor ischaemic factors and prognosis for transient ischaemic attacks and minor ischaemic
strokes. The Oxfordshire community stroke project. Stroke 1986;20:1494-9.

12 Epidemiological Resources Incorporated. EGRET: epidemiological graphics, estimation and testing. Seattle, Washington: Epidemiological Resources, 1988

13 Cox DR. Regression models and life-tables. Fournal of Royal Statistical Society 1972;B34:187-220.

14 Cox DR, Oakes D. Analysis of survival data. London: Chapman and Hall, 1984

15 Hankey GJ, Slattery JM, Warlow CP. Transient ischaemic attacks. Which patients are at high (and low) risk of serious vascular events? I Neurol Neurosurg Psychiatry 1992;55:640-52.

16 Bamford J, Sandercock P, Dennis M, Warlow C, Jones L, McPherson K, et al. A prospective study of acute cerebrovascular disease in the community: the Oxfordshire community stroke demography and incident cases of first-ever stroke. 7 Neurol Neurosurg
Psychiatry 1988;51:1373-80.

7 Dennis MS, Bamford JM, Sandercock PAG, Warlow CP. Incidence of transient ischaemic attacks in Oxfordshire, England. Stroke 1989;20:333-9.

18 Donnan GA, McNeil JJ, Adena MA, Doyle AE, O'Malley HMO, Neill GC. Smoking as a risk factor for cerebral ischaemia. Lancet 1989;ii:643-7.

19 Campbell A, Caird FI, Jackson TFM. Prevalence of abnormalities of electrocardiogram in old people. Br Hear f 1974;36:1005-11.

20 Rose G, Baxter PJ, Reid DD, McCartney P. Prevalence and prognosis of electrocardiographic findings in middle-aged men. Br Hear $\mathcal{f} 1978 ; 40$ 636-43.

21 Kannel WB, Abbott RD, Savage DD, McNamara PM. Epidemiological features of chronic atrial fibrillation: the Framingham study. N Engl f Med 1982;306:1018-22.

22 Wolf PA, Abbott RD, Kannel WB. Atrial fibrillation as an independent risk factor for stroke: the Framingham study. Stroke 1991;22:983-8.

(Accepted 9 February 1993) 